\title{
A Quantitative Method for Estimating Probable Public Costs of Hurricanes
}

\section{MICHAEL R. BOSWELL ROBERT E. DEYLE* \\ RICHARD A. SMITH}

Florida Planning and Development Laboratory

Department of Urban and Regional Planning

Florida State University

Tallahassee, Florida 32306-2280, USA

\section{E. JAY BAKER}

Department of Geography

Florida State University

Tallahassee, Florida 32306-2050, USA

ABSTRACT / A method is presented for estimating probable public costs resulting from damage caused by hurricanes, measured as local government expenditures approved for reimbursement under the Stafford Act Section 406 Public Assistance Program. The method employs a multivariate model developed through multiple regression analysis of an array of independent variables that measure meteorological, socioeconomic, and physical conditions related to the land-

Local governments in the United States spend large sums of money each year for hurricane response and recovery efforts. Between 1979 and 1996, for example, losses to local governments in the State of Florida totaled nearly $\$ 650$ million for presidentially declared disasters. Hurricane Andrew, alone, generated more than $\$ 550$ million in local government losses in the state. These costs are likely to rise given continuing coastal development, increasing potential for hurricanes (Gray 1996), and changing federal and state cost-sharing formulas.

In recent decades higher levels of government in the United States have stepped in to help local governments pay the costs of responding to and recovering from disasters. The Public Assistance Program under the Stafford Act (Robert T. Stafford Disaster Relief and Emergency Assistance Act of 1988, Public Law 100-707) governsfederal disaster assistance to local governments. The statute authorizes the federal government to reim-

*Author to whom correspondence should be addressed. fall of hurricanes within a local government jurisdiction. From the regression analysis we chose a log-log (base 10) model that explains $74 \%$ of the variance in the expenditure data using population and wind speed as predictors. We illustrate application of the method for a local jurisdiction-Lee County, Florida, USA. The results show that potential public costs range from $\$ 4.7$ million for a category 1 hurricane with winds of 137 kilometers per hour ( 85 miles per hour) to $\$ 130$ million for a category 5 hurricane with winds of 265 kilometers per hour ( 165 miles per hour). Based on these figures, we estimate expected annual public costs of $\$ 2.3$ million. These cost estimates: (1) provide useful guidance for anticipating the magnitude of the federal, state, and local expenditures that would be required for the array of possible hurricanes that could affect that jurisdiction; (2) allow policy makers to assess the implications of alternative federal and state policies for providing public assistance to jurisdictions that experience hurricane damage; and (3) provide information needed to develop a contingency fund or other financial mechanism for assuring that the community has sufficient funds available to meet its obligations.

burse local governments for $75 \%$ of their expenditures for debris removal, emergency protective measures, and repair of public buildings, facilities, and infrastructure. State governments have typically covered at least half of the nonfederal share of these expenditures. Thus, local governments could anticipate having to cover only $12.5 \%$ of the costs of disaster response and recovery. More recently, beginning with H urricane H ugo in 1989 , the federal government has assumed either $90 \%$ or $100 \%$ of the response and recovery costs eligible for reimbursement under the public assistance program. In Florida, the state has covered $100 \%$ of the nonfederal share in recent disasters, thereby relieving local communities of any fiscal responsibilities for these storm costs.

However, provision of this external support to local governments is not consistent with the objectives of good land-use planning or sustainable communities. Beatley (1998, p. 243) argues that sustainable communities must be disaster resilient, i.e., "they can survive and prosper in the face of major natural events." Planners and other policy analysts have identified an array of initiatives that local governments can take to increase disaster resilience (Beatley 1998, Berke and Beatley 1992, Burby and others 1991, Deyle and Smith 1994, 
Godschalk and others 1989, 1998, Olshansky and Kartez 1998). The most obvious is to avoid development of hazardous areas or to abandon hazardous areas that are al ready developed. H owever, where significant benefits can be derived from such development, communities can take measures to reduce the risks of damage and injury. These include making existing buildings and infrastructure more resistant to damage (e.g., more stringent building codes), altering the environment to reduce exposure to hazards (e.g., building dams and seawalls), protecting and enhancing natural features such as dunes and floodplain wetlands (e.g., beach renourishment), and converting developed land to less vulnerable uses (e.g., converting residential or commercial development to open space or recreational uses).

Indeed, federal and state governments have taken initiatives to encourage local governments to more adequately mitigate natural hazards. These have included financial incentives and planning mandates designed to encourage local governments to develop policies and plans for hazard mitigation and poststorm recovery (Olshansky and Kartez 1998, Platt 1998). Thus, for example, under the National Flood Insurance Act in the U nited States, local governments must adopt a flood control ordinance for their constituents to be eligible to purchase federally managed flood insurance, and flood insurance premiums are reduced in communities that take additional measures to reduce their vulnerability to flooding. The states of N orth Carolina and Florida (USA) require local governments to include hazard mitigation and postdisaster redevelopment components in their comprehensive land-use plans.

The response to federal and state programs to foster mitigation initiatives by local governments has been, largely disappointing, however. For example, while most local governments have taken the minimum steps necessary to be eligible for the National Flood Insurance Program, few have responded to the incentives offered under the Community Rating System to develop more effective, integrated strategies for reducing flood hazards (O Ishansky and Kartez 1998). While state planning mandates have been shown to increase the numbers of localities that address natural hazards in their comprehensive plans (Burby and others 1996), local plans do not consistently comply with the detailed requirements of the mandates (Deyle and Smith 1998). Where local plans contain policies that address hazard mitigation, those policies are often ignored in day-today decision making (Smith and Deyle 1997b). Local efforts that have been taken to mitigate future damage have typically been limited to those that are politically expedient and low in local costs; these efforts have had little impact on the national costs of hur ricane disasters (Olshansky and Kartez 1998).

Current practices of federal and state governments assuming all or most of the costs of hurricane damage under the public assistance program may have stimulated local governments to minimize their mitigation and planning efforts (Burby and others 1998). Indeed, with the costs being paid by other levels of government, local communities have little incentive to control landuse development in ways that may reduce local tax revenues as they reduce hurricane damage potential. Such reliance on external sources of relief is not consistent with the concept of sustainable disaster resilience, especially where communities have the means to avoid or reduce exposure or vulnerability to natural hazards. One of the equity principles advanced by advocates of sustainable devel opment is that individuals or groups who are responsible for costs to society at-large should pay an appropriate share of the costs they induce (Beatley 1998, Berke 1995, Smith and Deyle 1997a). Thus where communities have chosen to develop hazardous areas so as to realize other social or economic benefits, they should not rely on the subsidies of external financial aid to cope with periodic damages that occur when disasters strike.

The federal government, and some states, have begun to discuss measures to hold local governments more accountable for the costs associated with repair of public buildings and infrastructure. The State of Florida has recently retrenched on the issue of disaster assistance to local governments with enactment of a law that reasserts the former state policy of paying only $50 \%$ of the nonfederal share of eligible public assistance program costs (S.B. 2400, 29th Florida Legislature, 1997). Federal policy makers are also considering alternative formulas governing public assistance. For example, the Federal Emergency Management Agency's $1995 \mathrm{Na}$ tional Performance Review, Phase 2 report (FEMA 1995) recommends a minimum nonfederal "deductible" of $\$ 5$ per capita for public facilities and infrastructure and a $\$ 75$ per capita threshold for any increases in the federal cost-sharing formula. Thus, for eligible public assistance costs that total up to $\$ 75$ per capita, the cost-share formula would remain at $75 \% / 25 \%$; only for costs greater than $\$ 75$ per capita would the maximum cost-share formula go to $90 \% / 10 \%$.

With an increased likelihood of having to pay a greater share of disaster costs, local governments are likely to be more concerned with reducing these costs and with securing local financial resources for paying these costs. Under these circumstances, local governments need the means to estimate the costs of response and recovery so that they can adequately capitalize a 
contingency fund or other means of financing the local share of disaster response and recovery. Such information will also help local governmentsin determining the cost-effectiveness of alternative mitigation strategies. An estimation method also would allow state and federal governments to better anticipate the likely costs of providing financial assistance to local governments struck by hurricanes.

In this paper, we describe a method for estimating public costs resulting from damage caused by hurricanes and apply the method to a specific local jurisdiction-Lee County, Florida, USA. The method employsa multivariate model developed through multiple regression analysis of an array of variables that measure meteorological, socioeconomic, and physical conditions related to the landfall of hurricanes. Our results show that the method holds considerable potential for use by local and higher levels of government.

In the following sections we explain the context of our development of this estimation method and describe related efforts to estimate various components of the costs of hurricanes. We then detail the approach taken to develop the model upon which the method is based and illustrate its use for both vulnerability assessment and risk analysisusing the example of L ee County. We conclude with a discussion of how the model upon which the method is based can be enhanced through further research.

\section{Context}

We initiated development of this public cost estimation method as part of a project undertaken in collaboration with Lee County. The goal of the project is to design a practical method for local governments to redistribute the costs of planning, preparedness, response, and mitigation for hurricanes away from the general taxpayer and toward the property owners that depend most heavily on these services. We are using Lee County as a pilot case to design a tax or fee system for such services that is based on measures of the differential risk associated with developed land in the county. The system developed in Lee County can then be adapted for use by other local governments in Florida and elsewhere in the U nited States.

Development of the tax/ fee system requires estimation of the expected annual local costs for response and recovery that would not be covered by federal or state public assistance. These estimates, combined with estimates of ongoing costs of planning, preparedness, and mitigation, can be used to establish the expected annual monetary demand for emergency management ser vices generated by each property owner in the county due to hurricanes. A tax/ fee mechanism can then be designed to generate the revenues needed to cover these costs to the local government more equitably than through general revenues raised from ad valorem property taxes.

\section{Other Initiatives to Estimate Natural Disaster Costs}

A number of initiatives have been taken to estimate different components of the costs associated with hurricanes and other natural disasters. These initiatives vary in their methods and foci, but none encompasses the full range of the public costs of response and recovery. They include hurricane loss studies initiated by the US Army Corps of Engineers and others; loss estimation methodologies for wind and flooding under development or recently developed by the National Institute of Building Sciences (NIBS) and a number of private consulting firms for the Federal Emergency Management Agency (FEMA) and other public agencies; and various models developed by and for the United States insurance industry.

Hurricane loss studies were prepared by various organizations-following a similar method-for most of the Gulf and south Atlantic coastal states in the U nited States (see for example SWFRPC 1982, Ruch 1983, USACE 1990). These studies were generally designed to estimate the range of economic impacts of hurricanes, "including potential property loss, employment loss, and loss to other sectors of the economy, such as agriculture" (SWFRPC 1982). While loss estimates were generated for multiple damage scenarios based on both storm-surge flooding and wind, the method relied on several simplifying assumptions about the relationships between broad categories of land use and the dollar value of property damage. This method was acceptable for providing regional estimates of potential hurricane losses, but it could not provide the level of precision desired by local governments for estimating losses linked to local land uses and property values. Asa result, there has been a decline in its use, at least in Florida ( $M$. McDonald, DCA-DEM, personal communication 1993).

Recent initiatives to estimate the costs associated with hurricanes build on the basic approach taken in the hurricane loss studies: deterministic models are used to estimate the extent of damage that will result to different types of structures exposed to the forces of wind, still-water flooding, and waves; estimates of structural damage are then converted into estimates of direct dollar losses and secondary economic impacts. For example, the National Institute of Building Sciences (NIBS) is currently developing regional loss estimation 
methods for flooding and wind under contract with FEM A modeled after a recently completed method for earthquakes (P. Schneider, NIBS, personal communication 1997). The NIBS system estimates direct dollar losses due to physical damage to general building stock, critical facilities, and transportation and utility systems; casualities; business interruption losses; secondar y economic impacts; and social impacts such as the demand for sheltering (National Institute of Building Sciences 1997). The method estimates some of the elements of the public costs of response and recovery, namely, debris generation, shelter demand, and repair costs for damage to public facilities and infrastructure, but it does not include actual costs for the major public cost categories of debris removal and protective measures (such as evacuation, overtime police and fire protection, and emergency flood protection).

Greenwood and Hatheway (1996) summarize a method developed by Michael Baker Corporation for FEMA's emergency support teams that was used during the approach of Hurricane O pal in 1995 to generate maps and dollar estimates of damage to public and private structures based on damage algorithms. The Baker method uses a geographic information system and county databases on public and private structures and facilities to estimate potential damage from stormsurge flooding and wind, but it does not explicitly estimate all of the public costs of response and recovery.

Similar approaches have been taken by Science Applications International Corporation (SAIC) in developing the Consequences Assessment Tool Set (CATS) for FEMA and the federal Defense Special Weapons Agency and by Watson Technical Consulting in developing a hurricane damage model (TAOS) for the Organization of American States. SAIC's CATS model produces real-time and simulation estimates of ordinal levels of damage bystructure type from wind storms and storm surge as well as earthquakes and various technological disasters (J. Pickus, Science Applications I nternational Corp., personal communication 1997). While CATS can facilitate comparisons of relative levels of total damage, the method is not designed to generate explicit dollar estimates of public costs of response and recovery. Watson'sTAOS usesa unique storm-surge and wind model to estimate damage to various types of private structures and public facilities, and it is also capable of estimating debris generation and secondary economic impacts (Watson 1995, C. C. Waton, Watson Technical Consulting, personal communication 1997). Again, however, it does not include the full range of public costs of response and recovery.

Other deterministic models have been produced for use by the United States insurance industry to predict insured losses. A comprehensive review of the extant models was conducted by the Florida Insurance Commissioner's Office in 1997 (J. Loomis, DCA-DEM, personal communication 1998). However, the models and the data on which they are based are not accessible to the public because of privacy and proprietary concerns. Because of the focus on insured losses, these model sare of limited utility to local governments concerned with estimating their own (public) costs of hurricane response and recovery.

Thus, most of the existing models estimate damage to public facilities and infrastructure from disasters, and a few estimate the amount of debris likely to be generated. None of them, however, estimates the full set of costs associated with local government response and recover $y$, including the costs of emergency protective measures such as evacuation and emergency police and fire protection, and the costs of debris removal and disposal. Yet our analysis of the five most recent hurricanes to strike the State of Florida shows that emergency protective measures and debris removal account for approximately $75 \%$ of the eligible public assistance costs incurred by local governments from hurricanes. While some insight has been gained from these other methods, the unique approach taken here develops a method that estimates both the costs of physical damage to local government facilities and infrastructure and the costs of local emergency management ser vices necessitated by hurricane response and recovery activities. In the following sections we describe the method in detail and demonstrate its use in estimating the probable costs of response and recovery for Lee County.

\section{A Public Cost Estimation Method}

This ap proach to estimating the costs to local governments of hurricane response and recovery differs from those described above in three fundamental ways. First, this approach is designed to support probabilistic risk analysis of the full range of possible storms as well as deterministic vulnerability analysis for selected storm scenarios. The other estimation methods are solely employed for deterministic analysis, although most could support probabilistic risk analysis. Second, we use empirical data from previous storms to estimate costs rather than theoretical models of the relationships between storm forces and damage to an array of different types of structures and facilities. O ur approach is simpler and requires fewer data than the other methods, in part because the objective is limited to estimating public costs and in part because the application only requires estimates for broad categories of expenditures rather than for many individual types of 
Table 1. Summary of hurricanes affecting the State of Florida, 1979-1995

\begin{tabular}{llclcr}
\hline Hurricane & Landfall date & $\begin{array}{c}\text { Hurricane } \\
\text { category }\end{array}$ & \multicolumn{1}{c}{$\begin{array}{c}\text { Affected } \\
\text { Florida region }\end{array}$} & $\begin{array}{c}\text { Number of } \\
\text { affected Florida } \\
\text { jurisdictions }\end{array}$ & $\begin{array}{c}\text { Total public } \\
\text { costs (US \$) }\end{array}$ \\
\hline Frederic & September 1979 & 4 & Northwest & 10 & 6.6 \\
Elena & September 1985 & 2 & Northwest and central & \\
Kate & November 1985 & 1 & Northwest & 40 & 7.8 \\
Andrew & August 1992 & 4 & South & 19 & 55 \\
Erin & August 1995 & 1 & Central and northwest & 76 & 21.5 \\
Opal & October 1995 & 3 & Northwest & 50 & 51.4 \\
\hline
\end{tabular}

aCosts in millions of 1996 dollars for Florida jurisdictions; costs for Andrew, Erin, and O pal not yet final.

'T These storms did not have a Florida landfall.

structures and facilities. The most important difference, however, is that this method encompasses the full array of public cost categories.

In the following sections we summarize the variables and data used in devising the public cost estimation method and the strategy followed to develop the model of the public cost function. We then present the results of our model analysis.

\section{Variables and Data}

The ideal dependent variable for such an estimation method would measure the total costs to local governments of hurricane response and recovery. We determined, however, from a review of available data for recent storms in Florida, that reliable data are only available for local government expenditures approved for reimbursement under the Stafford Act Section 406 Public Assistance Program. No systematic data are available for local costs of disasters that do not qualify for presidential disaster declarations. Furthermore, the preliminary damage assessments submitted by local governments for federal public assistance are not a reliable basis for estimating local costs that are not eligible for federal assistance, and local governments do not keep good records of other costs that are not submitted for federal public assistance. Thus estimates derived from empirical analysis of federal public assistance data are conservative estimates of the total costs for local governments resulting from hurricanes. By focusing exclusively on public assistance costs, however, such estimates can provide useful information to federal and state policy makers who wish to estimate likely public costs that result from presidential disaster declarations.

We obtained data on public expenditures for five presidentially declared disasters that occurred in Florida between 1979 and 1995 (Table 1) by examining current and historical records held by the Florida Department of Community Affairs, Division of Emergency Management. The records for recent disasters are held in a computer database, while data for older disasters are archived as printed forms. The records consist of summaries of approved public assistance damage claims submitted to FEMA under Section 406 of the Stafford Act. They contain a detailed description of the applicant jurisdiction, expenditure amounts by expenditure category, damage location, damaged facility, and a narrative description of the damage. The geographic and temporal limitations of the data set were based on the ability to obtain consistent data for the analysis. Including states other than Florida proved problematic for gathering data on many variables within the time and resource constraints of this project. Including disasters before 1979 proved problematic due to the inaccessibility of historic records.

The data for public expenditures were partitioned by disaster name and date and affected jurisdictions. This yielded 250 obser vations ( see Appendix A for a detailed listing) that represent the final approved expenditures for a presidentially declared disaster for individual jurisdictions, converted to constant 1996 dollars based on the Consumer Price Index (USBLS 1996). The jurisdictions include cities and unincorporated portions of counties from all areas of the state. We excluded expenditure claimants that were not general government units, e.g., school boards, sheriffs' offices, special districts, etc. The specific dependent variables analyzed include the total approved public assistance expenditures and expenditures for each of the seven federally defined expenditure categories, as follows: $A-$ debris removal; $B$ - protective measures; $C$-roads, signs, and bridges; $\mathrm{D}$-water control facilities; $\mathrm{E}$-buildings and equipment; F-public utilities; and G- parks and recreation, and other (see Appendix $B$ for details).

We developed 20 independent variables across four categories of factors associated with the public costs that result from coastal storms: (1) tropical cyclone variables, which measure the meteorological characteristics of the storm; (2) socioeconomic variables, which measure a set of population and housing value characteris- 
tics for a community; ( 3 ) development variables, which characterize land development of the coastal area of a community; and (4) physical variables, which measure the geographic characteristics of a community. The independent variables tested include the following ( see Appendix B for details) :

Tropical cyclone variables

Maximum sustained surface wind speed at jurisdiction (miles per hour)

Forward speed of tropical cyclone (miles per hour)

Quadrant of on-shore winds ( $0 / 1$ dichotomous)

Tropical cyclone angle of approach (degrees)

Entering tropical cyclone ( $0 / 1$ dichotomous)

Tropical cyclone surge ( $0 / 1$ dichotomous)

Tropical cyclone landfall ( $0 / 1$ dichotomous)

Socioeconomic variables

Population of jurisdiction (persons)

Population density of jurisdiction ( personsper square mile)

Population of jurisdiction at risk to storm surge (persons)

Median housing unit value (dollars)

Development variables

Beachfront low/ medium density residential existing land use (linear miles)

Beachfront high density residential existing land use (linear miles)

Beachfront commercial existing land use (linear miles)

Beachfront recreation/ conservation existing land use (linear miles)

Beachfront vacant existing land use (linear miles)

Physical variables

Land area of jurisdiction 1990 (square miles)

Beachfront length (linear miles)

Storm wave susceptibility quotient at high tide (percent $>$ moderate)

Beachfront jurisdiction (0/ 1 dichotomous)

Waterfront jurisdiction ( $0 / 1$ dichotomous)

Several constraints exist in the constructed data set.

First, variables for rainfall and tornado activity associated with hurricanes are not included, both of which affect damage levels. Rainfall data were unavailable at a sufficiently fine geographic scale and reliable tornado activity data are not gathered. A second constraint is the lack of readily available data on vegetative cover. Areas with more trees are likely to experience greater damage from falls and greater debris generation. Obtaining these data requires analysis of remote sensing databases, which was beyond the scope of this project. A third constraint is that Florida coastal physiography data ( which show characteristics such as dune height, beach width, and offshore slope) are only available for 1985. Because of the dynamic nature of much of the Florida coast, we thought it ill-advised to treat these variables as constants. A fourth constraint is the use of proxies (i.e., population and population density) to measure intensity of development in the jurisdiction and the lack of a measure of existing beachfront industrial land use. Finally, we were unable to obtain sufficiently accurate storm surge elevation data to measure this phenomenon as a continuous variable. A dichotomous variable was included to differentiate jurisdictions that were subject to storm surge forces.

\section{Strategy for Developing the Estimation Method}

We followed a seven-step procedure using regression analysis to develop and test numerous multivariate models for each of the seven expenditure categories of public assistance individually and in various combinations. The details are explained below.

1. Several model equation forms were selected and the data appropriately transformed.

2. Regression analyses were conducted on each dependent variable for each model form.

3. The data were partitioned based on maximum sustained surface wind speed.

4. Step 2 was repeated on the partitioned data set.

5. Various model diagnostics were conducted including outlier analysis.

6. Step 2 was repeated on the data set with outliers removed.

7. The optimal model for each form was selected based on sample size, and statistical tests of the explanatory power and significance of the model and its parameters.

Step 1: Model form. Inspection of the data revealed the likelihood that public costs are nonlinear. As shown in Table 2, mean local costs per capita increase geometrically with storm magnitude represented by the SaffirSimpson scale. Thus, we developed several nonlinear regression model forms, along with a linear model for comparison. The nonlinear models included log-log, semilog (both log-linear and linear-log), and polynomial equational forms. The logarithmic forms used the natural log (base e) and the common log (base 10). The polynomial forms were of first, second, and third order.

Steps 2, 4, and 6: Regression analyses. We conducted numerous preliminary regression runs (using SAS software version 6.0) to produce the "best" model for each equational form and dependent variable using a procedure to generate models with the best adjusted $R^{2}$ values based on all the independent variables (SAS Institute 1990). We retained those models in which the 
Table 2. Per capita public costs by hurricane categorya

\begin{tabular}{|c|c|c|c|c|c|c|}
\hline \multirow[b]{2}{*}{$\begin{array}{l}\text { Hurricane } \\
\text { category }\end{array}$} & \multirow[b]{2}{*}{$\begin{array}{l}\text { Maximum sustained } \\
\text { winds (kph) }\end{array}$} & \multicolumn{4}{|c|}{ Cost (US\$) } & \multirow[b]{2}{*}{$\begin{array}{l}\text { Number of } \\
\text { observations }\end{array}$} \\
\hline & & Mean & $\begin{array}{l}\text { Standard } \\
\text { deviation }\end{array}$ & Minimum & Maximum & \\
\hline 1 & $119-153$ & 44.40 & 66.00 & 0.30 & 397.50 & 61 \\
\hline 2 & $154-178$ & 91.80 & 76.50 & 27.80 & 296.30 & 14 \\
\hline 3 & $179-210$ & 220.80 & 274.60 & 14.60 & 1029.20 & 12 \\
\hline 4 & $211-249$ & 820.50 & 382.10 & 283.00 & 1138.60 & 3 \\
\hline
\end{tabular}

aCategory 5 ( $>249 \mathrm{kph}$ ) storms were not included because there were no observations.

Table 3. Regression analysis results

\begin{tabular}{lccccc}
\hline Model statistics & Linear & Log-loga & PolyA & PolyB & PolyC \\
\hline Dependent mean $(\mu)$ & $\$ 2,354,309$ & $\$ 2,379,372$ & $\$ 1,790,333$ & $\$ 1,790,333$ & $\$ 1,790,333$ \\
Standard error $(\mathrm{SE})$ & $\$ 4,442,890$ & $\$ 3,846,703$ & $\$ 1,900,264$ & $\$ 2,342,584$ & $\$ 1,874,001$ \\
SE/ $\mu$ ratio & 1.89 & 1.62 & 1.06 & 1.31 & 1.05 \\
Adj. R 2 & 0.547 & 0.737 & 0.894 & 0.838 & 0.897 \\
F-test significance & 0.0001 & 0.0001 & 0.0001 & 0.0001 & 0.0001 \\
$N$ & 89 & 82 & 84 & 84 & 84 \\
\hline
\end{tabular}

aBase 10.

regression coefficients for the independent variables were significant at the 0.25 level for the test and which had the highest adjusted $R^{2}$ values. The t test threshold was set at this level so that it would not dominate model specification.

Step 3: Data set partitioning. We hypothesized that the independent variable maximum sustained surface wind speed may have a discontinuous relationship to public costs because critical thresholds of wind speed may exist with respect to the amount of damage that occurs. Therefore, we experimented with partitioning the data set by maximum sustained surface winds greater than or equal to 119 kilometers per hour ( 74 miles per hour), which is the minimum for hur ricane designation.

Step 5: Model diagnostics. We used the studentized residual diagnostic to identify outlying values of the dependent variable-total expenditures or expenditures by category-and removed all obser vations from the data set where the studentized residual exceeded 2.0 (Belsley and others 1980). In addition, we checked for multicollinearity and heteroscedasticity, but both were of little consequence.

Step 7: Selection of optimal models. We evaluated models of the same equational form against the following criteria: (1) number of observations greater than 35; (2) all regression coefficients significant at the $P \leq 0.25$ for the $t$ test; (3) adjusted $R^{2}>0.50$; (4) model significant at $P \leq 0.05$ for the $F$ test; and ( 5 ) low ratio of the standard error of the estimate to the dependent mean.

\section{Results of Regression Analysis}

Several findings from our analysis of alternative models are notable. First, partitioning the data set by maximum sustained surface wind speed was important. No regression run that included observations with wind speed values of less than 119 kilometers per hour ( 74 miles per hour) produced an adjusted $R^{2}$ above 0.50 . Second, the models using the dependent variable of total final approved expenditures for all expenditure categories, rather than any of the expenditure categories individually or in combination, consistently outperformed the others. Third, the independent variables maximum sustained surface wind speed and population of jurisdiction consistently met the test criterion in all model specifications. Most other independent variables did not.

Application of our model testing criteria generated models of five forms (Table 3). The equations for each regression model are specified as follows:

Linear: $Y=-16547009+183918($ WIND) + 74.56(POP_TOT) - 211.88(POP_DENS)

Log-log $($ base 10) $: \log Y=-7.7 \overline{7}+4.98(\log W I N D)+$ 0.90( $\log$ POP_TOT)

Poly $A:{ }^{-} Y=-2042821+316.55\left(\right.$ WIND) ${ }^{2}$ $+6.58($ POP_TOT $)+9.27 \mathrm{E}^{-10}\left(\mathrm{POP}_{-} \mathrm{TOT}\right)^{3}$

Poly B: $\bar{Y}=-3075930+404.44(\text { WIND })^{2}+$ 3.13E ${ }^{-4}\left(\right.$ POP_TOT $^{3}$

Poly $C: \bar{Y}=-976532+2.22(\text { WIND) })^{3}+$ $9.81 \mathrm{E}^{-10}\left(\mathrm{POP}_{-} \mathrm{TOT}\right)^{3}$ 
Table 4. Regression model comparison—public costs for Lee County

\begin{tabular}{cccccc}
\hline \multirow{2}{*}{$\begin{array}{c}\text { Hurricane } \\
\text { categorya }\end{array}$} & \multicolumn{3}{c}{ Cost (US \$) } & Poly B & Poly C \\
\cline { 2 - 6 } & Linear & Log-log & Poly A & $18,082,443$ & $14,204,168$ \\
\hline 1 & $16,932,276$ & $4,656,548$ & $14,875,601$ & $19,485,334$ & $15,292,454$ \\
2 & $20,334,759$ & $12,479,497$ & $15,973,631$ & $21,067,189$ & $16,753,423$ \\
3 & $23,553,324$ & $27,261,115$ & $17,211,733$ & $23,349,732$ & $19,229,868$ \\
4 & $27,507,561$ & $61,742,278$ & $18,998,257$ & $26,205,463$ & $22,852,113$ \\
5 & $31,737,675$ & $130,382,365$ & $21,233,411$ & 263 & \\
\hline
\end{tabular}

aM id-range values were used for maximum sustained surface wind speeds for each storm category.

where WIND = maximum sustained surface wind speed at jurisdiction (miles per hour), POP_TOT $=$ total population of jurisdiction (persons), and POP_DENS = population density of jurisdiction (persons per square mile). The coefficients correspond to nonmetric measures of the variables as reported in Appendix B.

\section{Evaluation of Regression Models}

In addition to evaluating the various model parameters, we used the five alternative regression models to estimate potential public costs in Lee County for each hurricane category (Table 4) and to estimate actual public costs for individual jurisdictions for the storms in the original data set. The polynomial models (poly A, poly $B$, and poly $C$ ) generally outperform the others on the statistical criteria (Table 3 ): adjusted $R^{2}$ values are higher, and the ratios of the standard error of the estimate to the dependent mean are lower (although in all cases the standard error is higher than the dependent mean). H owever, the small amount of variation in cost estimates across the five hurricane categories produced by the polynomial models is of concern (Table 4). Our per-capita analysis (Table 2) suggests that the variation in public costs across hurricane categories will be significantly larger than the approximately 33\% indicated by the polynomial models. The small variation occurs in the polynomial models because the total population variable, which does not vary when applied to a single jurisdiction, is cubed in the equation. The low adjusted $R^{2}$ value and high relative standard error in the linear model are reason enough for rejection. Thus the log-log (base 10) model emerges as the best compromise. In addition, the log-log model performs best at estimating actual costs for individual jurisdictions in the original data set.

\section{Application to Lee County, Florida}

The log-log cost model can be used to estimate both the total costs of local response and recover y likely to be eligible for federal public assistance under different hurricane scenarios and the amount a local jurisdiction
Table 5. Estimates of response and recovery costs at mid-range wind speeds for hurricane categories for Lee County

\begin{tabular}{crrr}
\hline & \multicolumn{3}{c}{ Cost (US \$) } \\
\cline { 2 - 4 } Hurricane & $\begin{array}{c}\text { Mid-range } \\
\text { total eligible }\end{array}$ & $\begin{array}{c}\text { Mid-range } \\
\text { local share } \\
(12.5 \%)\end{array}$ & $\begin{array}{c}\text { Mid-range } \\
\text { local share } \\
\text { under 1995 } \\
\text { FEM A proposal }\end{array}$ \\
\hline 1 & $4,656,548$ & 582,069 & $1,636,724$ \\
2 & $12,479,497$ & $1,559,937$ & $2,614,592$ \\
3 & $27,261,115$ & $3,407,639$ & $3,776,733$ \\
4 & $61,742,278$ & $7,717,785$ & $5,500,791$ \\
5 & $130,382,365$ & $16,297,796$ & $8,932,796$ \\
\hline
\end{tabular}

might be responsible for under different federal and state cost-sharing policies. The model also can be used to calculate an expected annual cost of response and recover $y$ based on the joint probability of a jurisdiction experiencing hurricanes of different magnitudes. Here we illustrate these applications for Lee County, which is located on the southern Gulf Coast of Florida. The unincorporated county had a 1996 population of 241,604 persons, a density of 361 persons per square mile, and a 1996-1997 budget of $\$ 527$ million divided almost evenly between operating and capital expenses.

\section{Vulnerability Analysis for Individual}

Hurricane Scenarios

Table 5 presents the range of estimated total local response and recovery costs likely to be eligible for federal public assistance under the Stafford Act for hurricanes that result in a presidential declaration. These are based on mid-range values for maximum sustained surface wind speed for each hurricane category. The mid-range costs vary from $\$ 4.7$ million for a category 1 hurricane with winds of 137 kilometers per hour ( 85 miles per hour) to $\$ 130$ million for a category 5 hurricane with winds of 265 kilometers per hour ( 165 miles per hour). The table also shows that if the statutory federal cost-share formula of $75 \%$ federal/ $25 \%$ nonfederal were applied, and the recently enacted 
state policy of splitting the nonfederal share equally with the jurisdiction were in force, Lee County's obligations for expenditures eligible for federal public assistance would range from $\$ 580,000$ for a category 1 hurricane to $\$ 16$ million for a category 5 hurricane. If, however, the federal government were to adopt a cost-sharing policy similar to that proposed in FEMA's 1995 National Performance Review (described above), Table 5 shows that Lee County's obligations would increase for lower intensity hurricanes-for example, to $\$ 1.6$ million for a category 1 hurricane-and decrease substantially for the most catastrophic hurricanes-for example the local share would be approximately $\$ 9.0$ million for a category 5 hurricane. These differences are the result of the proposal's $\$ 5$ per capita "deductible" and the $\$ 75$ per capita damage threshold, above which FEMA would provide more assistance than is the current policy.

\section{Risk Analysis for Contingency Fund Capitalization}

Where a jurisdiction chooses to establish the financial means to cover its potential financial obligations for the costs of response and recovery to a presidentially declared natural disaster, a probabilistic analysis can provide guidance on the rate at which revenues might be raised to capitalize a dedicated contingency fund. Calculation of the expected annual public costs for hurricane damages requires two sets of data: (1) estimates of the local costs associated with the range of hurricane-force winds that could potentially affect the jurisdiction, and (2) estimates of the return periods for specific wind speed ranges for the jurisdiction.

Estimates of local costs can be cal culated for 1-kilometer-per-hour increments in maximum sustained surface wind speeds using the log-log model similar to the process summarized by Table 4 . Return periods for specific locations can be calculated following the methods detailed in the National H urricane Center's ( N HC) HURISK technical memorandum (Neumann 1987) and using the associated HURISK risk analysis program. The HURISK program generates equations, based on empirical data, for calculating the percentage occurrence of storms with different maximum sustained surface wind speeds and for calculating the number of storms passing within a specified distance of a given point. Calculations based on these two equations provide return periods for each of the different hurricane categories for a jurisdiction. We modified the HURISK method to more accurately convert point return periods to areal return periods and to estimate return periods for maximum sustained surface winds instead of the center of storms. The expected annual public costs can then be calculated using the areal return
Table 6. Estimates of expected annual response and recovery costs for Lee County

\begin{tabular}{lccc}
\hline & & \multicolumn{2}{c}{ Cost (US \$) } \\
\cline { 3 - 4 } Hurricane & $\begin{array}{c}\text { Annual } \\
\text { probability of } \\
\text { category }\end{array}$ & $\begin{array}{c}\text { Expected } \\
\text { annual } \\
\text { occurrence (\%) }\end{array}$ & $\begin{array}{c}\text { Expected } \\
\text { tonnual } \\
\text { local share } \\
(12.5 \%)\end{array}$ \\
\hline 1 & 6.15 & 279,697 & 34,962 \\
2 & 2.20 & 263,262 & 32,908 \\
3 & 1.61 & 424,807 & 53,101 \\
4 & 0.86 & 533,042 & 66,630 \\
5 & 0.45 & 776,659 & 97,082 \\
Total & 11.27 & $2,277,467$ & 284,683 \\
\hline
\end{tabular}

periods and the cost estimates for each wind speed increment. Multidecadal variability in the frequency of hurricane activity in the Atlantic-related to phenomena such as EI Niño and rainfall in western Africa (Gray and others 1997) - will not affect the long-term average cost figure.

Application of this analysis to Lee County is summarized in Table 6. The local share of expected annual costs of $\$ 284,683$ represents the likely local expenditures required in any given year for hurricane response and recovery efforts. The county could use this as the target amount of revenue to raise each year for a contingency fund until the fund balance reaches some maximum. The cap might be set at the estimated mid-range local costs associated with a category 5 hurricane ( $\$ 16$ million where the local share is $12.5 \%$ ) or another figure deemed appropriate by local policy makers.

\section{Discussion}

This exploratory work demonstrates the feasibility of developing an estimation method for the public costs of hurricane response and recovery activities and the utility of the estimates that can be produced by such a method. The log-log model explains $74 \%$ of the variance in the expenditure data we analyzed from 82 jurisdictions for five hurricanes that have affected Florida communities since 1979. The estimates generated of the local costs associated with the range of maximum sustained surface wind speeds for Lee County offer useful guidance for anticipating the magnitude of the federal, state, and local expenditures that could be required for the array of possible hurricane scenarios that could affect that jurisdiction. These estimates also allow policy makers to assess the implications of alternative federal and state policies for providing public assistance to jurisdictions that experience hurricane damage that warrants a presidential disaster declara- 
tion. In addition, the expected annual local cost estimatesillustrate how such a method can be employed by local policy makers to determine how to capitalize a contingency fund or other financial mechanism for assuring that the community has sufficient funds available to meet its obligations under extant federal and state policies governing public assistance for natural disasters.

This preliminary method offers a capability that supplements the cost estimation methods developed by others. While existing estimation methods rely principally on deterministic models of damage to private and/ or public structures, ours provides estimates that include other elements of the local costs of hurricanes, including debris removal and disposal and provision of emergency protective services that make up approximately 75 percent of total local costs of response to and recovery from hurricanes. This method derives cost estimates from empirical data from previous storms rather than from theoretical models of the relationships between the physical forces of storms, the structural characteristics of buildings and facilities, and resultant damages.

The model upon which this method relies can be enhanced through additional research. Expansion of the data base to include other storms with a wider array of storm tracks, wind speeds, rainfall, storm surge, and other relevant storm parameters would provide a more robust model that better approximates the full range of possible coastal storm scenarios. Such an expanded database could enable extending the model to tropical cyclones with maximum sustained surface wind speeds of less than 119 kilometers per hour ( 74 miles per hour). To do so requires gathering data for presidentially declared disasters in states other than Florida. FEMA does not have a central database that contains the necessary data to build such a model, but apparently the data can be obtained from FEMA's regional offices (C. Stewart, FEM A, personal communication 1997).

This model could also be enhanced by testing additional variables for which we were not able to obtain adequate data within our time and resource constraints. Further investigation may uncover satisfactory measures for rainfall, storm surge, and some indication of the presence of tornado activity. Vegetative cover data are available from various remote sensing sources and should be amenable to inclusion in an expanded method. Adequate coastal physiography data (i.e., nearshore bathymetry and beach profiles) are probably not readily available for all of the times and locations that would be included in a more extensive storm database. Detailed historical data on building stock and infrastructure such as those used in several of the deterministic damage loss estimation methodologies may be difficult to obtain for many jurisdictions. It may be possible, however, to use more general parameters such as age of structure and applicable building code requirements to roughly characterize the vulnerability of structures to damage from wind and flooding. Such additions could enhance the explanatory power of the model and reduce the ratio of the standard error to the dependent mean.

I deally, a public cost estimation model should encompass all of the local costs of hurricane response and recovery. This model is limited to estimating expenditures eligible for federal and state cost sharing under the Stafford Act Public Assistance Program. Expansion of the model to include expenditures not eligible for federal or state reimbursement as well as the costs incurred byjurisdictions that do not qualify for presidential disaster declarations would require standardized record keeping that differs significantly from the typical accounting practices of local governments. Thus, the development of such data seems unlikely. Insight into the magnitude of the differences between expenditures eligible for federal public assistance and the other costs borne by local governments could, perhaps, be developed from case studies of future disasters. H owever, the substantial pressures under which local officials must operate during disaster response and recovery may make this difficult.

Ultimately, the value of a public cost estimation method depends on how the method is used. Lee County, our collaborator in this project, intends to use the results of our analysis to establish a risk-based system for assessing the owners of developed land for the emergency management services they consume. This application raises many other methodological and legal issues that we deal with elsewhere (see Smith and Deyle 1997a, Falconer and others 1996). This research, and that of other natural hazards scholars, suggests that significant reductions in the national costs of natural disasters will not occur until the incentives for local governments to undertake significant mitigation are increased. Research is needed to determine what levels of local fiscal responsibility will significantly alter the attitudes and behaviors of local officials. Federal and state assumption of $100 \%$ of the major costs of response and recover $y$ is clearly sending the wrong signal. Recent changes enacted or contemplated by the State of Florida and FEMA represent useful revisions to this policy. Such policy changes not only have the potential to alter behavior, but they will also firmly establish the need for a method to better estimate the local costs of natural disaster response and recovery. 


\section{Acknowledgments}

This research was conducted under the auspices of the Florida Sea Grant College Program, with support from the National $O$ ceanic and Atmospheric Administration, Office of Sea Grant, US Department of Commerce, Grant No. R/ C-P-21. The authors gratefully acknowledge the assistance provided by the staff of the Florida Department of Community Affairs, Bureau of Recovery and Mitigation, in procuring data on public expenditures for Florida hurricanes, and the National Hurricane Center, in procuring data on hurricane tracks, intensities, and return periods. In addition the authors thank Robert Simpson and Ian Burton for their helpful comments on an earlier draft of this article.

\section{Appendix A: Observations Used in Public Cost Estimation Method}

The following is a list of all counties that contain jurisdictions with approved public assistance damage claims submitted to FEMA under Section 406 of the Stafford Act for presidentially declared hurricane disasters that occurred in Florida between 1979 and 1995. The number of jurisdictions in each county is shown in the parentheses. Where that number is zero, claims were submitted by the county only. Some of the jurisdictions had multiple presidentially declared hurricane disasters during this time.

Bay County ( 8 )
Brevard County ( 14)
Broward County (24)
Calhoun County (1)
Collier County (2)
Dade County (24)
Dixie County (1)
Escambia County (3)
Franklin County (2)
Gadsden County (3)
Gulf County (2)
Hernando County (1)
Hillsborough County (2)
Holmes County (4)
Indian River County (1)
Jackson County (4)

Jefferson County (1)

Leon County (1)

Levy County (1)

Liberty County (0)

Manatee County (5)

Monroe County (2)

O kaloosa County (9)

Orange County (8)

Pasco County (2)

Pinellas County (23)

Santa Rosa County (3)

St. Lucie County (1)

Taylor County (0)

Wakulla County ( 1 )

Walton County (3)

Washington County (1)

\section{Appendix B: Variables Used in Public Cost Estimation Method}

\section{Dependent Variables}

CAT_A-Final Approved Expenditures for Declared Storm, Category A: Debris Removal-costs to remove all disaster-induced debris on nonfederal public roads and water ways, other public property, and private property when managed by local government forces; also can include cost of demolition of public structures made unsafe by the disaster (1996 dollars). Source: Florida Department of Community Affairs, Division of Emergency Management (DCA-DEM); active and archived files.

CAT_B-Final Approved Expenditures for Declared Storm, Categor y B: Protective M easures-costs to implement emergency response measures designed to protect life, safety, property, and health including evacuation, police and fire service, sand bags, and barricades (1996 dollars). Source: DCA-DEM; active and archived files.

CAT_C-Final Approved Expenditures for Declared Storm, Category C: Roads, Signs, Bridges-costs to repair or replace nonfederal roads, bridges, streets, culverts, and traffic control devices (1996 dollars). Source: DCA-DEM ; active and archived files.

CAT_D_Final Approved Expenditures for Declared Storm, Category D: Water Control-costs to repair or replace dikes, dams, drainage channels, irrigation works, and levees (1996 dollars). Source: DCA-DEM ; active and archived files.

CAT_E-Final Approved Expenditures for Declared Storm, Category E: Buildings and Equipment-costs to repair or replace public buildings and equipment, damaged supplies and inventories, and public transit systems (1996 dollars). Source: DCA-DEM; active and archived files.

CAT_F-Final Approved Expenditures for Declared Storm, Category F: Public Utilities - costs to repair or replace damaged water supply systems, solid waste management facilities, sewerage systems, storm drainage systems, and telephone, light, electric, and gas supply utilities ( 1996 dollars). Source: DCA-DEM; active and archived files.

CAT_G-Final Approved Expenditures for Declared Storm, Category G: Parks \& Recreation, \& O ther-costs to repair or replace parks and recreational facilities or any other public facilities that do not reasonably fit under other categories (1996 dollars). Source: DCADEM; active and archived files.

TOTAL-Total of CAT_A through CAT_G - total final approved expenditures for all expenditure categories (1996 dollars) .

\section{Independent Variables}

Tropical cyclone variables. WIND-Maximum Sustained Surface Winds at Jurisdiction (miles per hour). Source: Calculated using MSSW, RMW, and DIST with figure 2.12 from Schwerdt and others (1979). 
MSSW-M aximum Sustained Surface Windsof Tropical Storm (miles per hour). The 1-min average wind speed at 10-m elevation; measured at closest point of approach to jurisdiction. Source: Storm track data from the National Hurricane Center ( NHC), Miami, Florida.

RMW-Radius of M aximum Sustained Winds (miles). Source: Calculated from MSSW using method in Darling (1991), Appendix C, and Simpson and Riehl (1981).

DIST-Distance of Tropical Cyclone Passage from Jurisdiction (miles). Measured as closest point of approach to jurisdiction. Source: Calculated using NHC storm track data.

SPEED-Forward Speed of Tropical Cyclone (miles per hour). Measured at closest point of approach to jurisdiction. Source: Calculated using NHC storm track data.

QUAD-Quadrant of Onshore Winds (dichotomous). Indicates whether the jurisdiction experienced onshore winds from the tropical cyclone during the duration of the event; $0=$ no onshore winds, $1=$ onshore winds. Source: Calculated using NHC storm track data.

ANGLE-Tropical Cyclone Angle of Approach (degrees). Indicates the tropical cyclone's approach angle relative to the coastline of the jurisdiction at closest point of approach; perpendicular approach $=90$ degrees, parallel approach $=0$ degrees. Source: Calculated using N H C storm track data.

ENTER-Entering Tropical Cyclone (dichotomous). Indicates whether the storm was entering, exiting, or overland (for noncoastal jurisdictions) at closest point of approach; 0 = exiting or overland, 1 = entering. Source: Calculated using NHC storm track data.

LANDFALL-Tropical Cyclone Landfall (dichotomous). Indicates whether storm made landfall in the jurisdiction; $0=$ no landfall, $1=$ landfall. Source: Calculated using NH C storm track data.

SU R GE-Tropical Cyclone Surge (interaction). This interaction variable is used to capture the effect of tropical cyclone induced storm surge on the jurisdiction. Source: Calculated as LANDFALL $*$ QUAD * ENTER * WATER.

Socioeconomic variables. POP_TOT_Population of Jurisdiction, Total (persons). For event year; projected from previous census count; unincorporated portion for counties. Source: BEBR (various dates 1980-1996).

POP_DENS-Population Density of Jurisdiction (persons per square mile). Source: Calculated from POP_TOT and LAND.

PÖP_RISK-Population of Jurisdiction At-Risk to Storm Surge (persons). Population at-risk to storm surge flooding, for event year. The DCA-DEM database reports total county population at risk (i.e., includes jurisdictions). Unincorporated county at-risk population was estimated assuming that it is the same proportion as the total county population at risk. For municipalities under 100,000 , all population is assumed to be at risk. For municipalities greater than 100,000 the proportional county ratio is applied. Source: DCA-DEM (1996).

RVAL_A-Median Housing Unit Value (dollars). The 1990 value adjusted to January 1996 using CPI for housing; counties include incorporated and unincorporated; cities under 1000 population are assigned county value. Source: Table 1 US Census (1990a); USBLS (1996).

Development variables. LMD_RES-Beachfront Low/ Medium Density Residential Existing L and U se (linear miles). Defined as less than 15 dwelling units per acre. Source: Fischer (1984).

HD_RES-Beachfront H igh Density Residential Density Existing Land U se (linear miles). Defined as greater than 15 dwelling units per acre. Source: Fischer (1984).

COMM - Beachfront Commercial Existing Land U se (linear miles). Source: Fischer (1984).

REC_CON-Beachfront Recreation/ Conservation Existing L and U se (linear miles). Source: Fischer (1984).

VACANT-Beachfront Vacant Existing Land Use (linear miles). Source: Fischer (1984).

Physical variables. LAND-Land Area 1990 (square miles). The 1990 land area; unincorporated portion for counties. Source: Table 8 U S Census (1990b).

LINEAR-Beachfront Total Linear Miles (linear miles). Source: Calculated as sum of LMD_RES, HD_RES, COMM, REC_CON, VACANT.

SWS_HT 1-Storm Wave Susceptibility Quotient at High Tide (percent $>$ moderate). Percentage of jurisdiction beachfront in categories Moderate $\mathrm{High}$ and $\mathrm{High}$. Source: Fischer (1984).

BEACH-Beachfront Jurisdiction (dichotomous). Beachfront jurisdiction; 0 = nonbeachfront, 1 = beachfront. Source: Fischer (1984).

WATER - Waterfront Jurisdiction (dichotomous). All beachfront jurisdictions plus jurisdictions on open water bodies (not including lakes); 0 = nonwaterfront, 1 = waterfront. Source: Florida map.

\section{Literature Cited}

Beatley, T. 1998. The vision of sustainable communities. In R. J. Burby (ed.), Cooperating with nature: Confronting natural hazards with land-use planning for sustainable communities. Joseph H enry Press, Washington, DC.

Belsley, D., A. E. Kuh, and R. E. Welsch. 1980. Regression diagnostics. John Wiley $\&$ Sons, New York, 292 pp. 
Berke, P. R. 1995. Natural-hazard reduction and sustainable development: a global assessment. Journal of Planning L iterature 9(4):370-382.

Berke, P. R., and T. Beatley. 1992. Planning for earthquakes: Risk, politics, and policy. Johns Hopkins, Baltimore, Maryland, $210 \mathrm{pp}$.

Burby, R. J., and others. 1991. Sharing environmental risks. Westview Press, Boulder, Colorado, 280 pp.

Burby, R. J., and others. 1996. Making governments plan: state experiments in managing land use. Johns Hopkins, Baltimore, Maryland, $192 \mathrm{pp}$.

Burby, R. J., and others. 1998. Policies for sustainable land use. In R. J. Burby (ed.), Cooperating with nature: Confronting natural hazards with land-use planning for sustainable communities. Joseph Henry Press, Washington, DC.

BEBR (Bureau of Economic and Business Research). 19801996. Florida statistical abstract. U niversity Press of Florida, Gainesville, Florida.

Darling, R. W. R. 1991. Estimating probabilities of hurricane wind speeds using a large-scale empirical model. Journal of Climate 4:1035-1046.

DCA-DEM (Florida Department of Community Affairs, Division of Emergency Management). 1996. Hurricane vulnerable population data. QuattroPro spreadsheet database. DCA-DEM, Tallahassee, Florida.

Deyle, R. E., and R. A. Smith. 1994. Storm hazard mitigation and post-storm redevelopment policies. Florida Planning and Development L aboratory, Florida State U niversity, Tallahassee, Florida, $321 \mathrm{pp}$.

Deyle, R. E., and R. A. Smith. 1998. Local government compliance with state planning mandates: The effects of state implementation in Florida. Journal of the American Planning Association (in press).

Falconer, M. K., R. A. Smith, and R. E. Deyle. 1996. Local government options for funding storm hazard management services. Florida Planning and Development Laboratory, Florida State U niversity, Tallahassee, Florida, 22 pp.

FEMA (Federal Emergency Management Agency). 1995. Report to the steering committee, national performance review, phase 2. FEMA, Washington, DC.

Fischer, D. W. 1984. U niversity of West Florida beach management study. University of West Florida, Pensacola, Florida, $940 \mathrm{pp}$.

Godschalk, D. R., D. J. Brower, and T. Beatley. 1989. Catastrophic coastal storms: hazard mitigation and development management. Duke University Press, Durham, North Carolina, $275 \mathrm{pp}$.

Godschalk, D. R., and others. 1998. Integrating hazard mitigation and local land-use planning. In R. J. Burby (ed.), Cooperating with nature: Confronting natural hazards with land use planning for sustainable communities. Joseph Henry Press, Washington, DC.

Gray, W. M. 1996. Predictions for the 1996 hurricane season. Paper presented at the 1996 National Hurricane Conference, 2-5 April 1996. O rlando, Florida.

Gray, W. M., J. D. Sheaffer, and C. W. Landsea. 1997. Climate trends associated with multidecadal variability of Atlantic hurricane activity. Pages 15-53, in H. F. Diaz and R. S. Pulwarty (eds.), Hurricanes: climate and socioeconomic impacts. Springer-Verlag, New York.

Greenwood, D. J., and D. J. H atheway. 1996. Assessing O pal's impact. Civil Engineering 66:40-43.

National Institute of Building Sciences. 1997. HAZUS earthquake loss estimation methodology user's manual. The Institute, Washington, DC, $450 \mathrm{pp}$.

Neumann, C. J. 1987. National Hurricane Center risk analysis program (HURISK). NOAA Technical Memorandum NWS NHC 38. NHC, Coral Gables, Florida, 55 pp.

Olshansky, R. B., and J. D. Kartez. 1998. Managing land use to build resilience. In R. J. Burby (ed.), Cooperating with nature: Confronting natural hazards with land-use planning for sustainable communities. Joseph Henry Press, Washington, DC.

Platt, R. H. 1998. Planning and land-use adjustments in historical perspective. In R. J. Burby (ed.), Cooperating with nature: Confronting natural hazards with land-use planning for sustainable communities. Joseph H enry Press, Washington, DC.

Ruch, C. 1983. Hurricane vulnerability analysis for Brazoria, Galveston, H arris, and Chambers counties. College of Architecture and Environmental Design, Texas A\&M University, College Station, Texas, 239 pp.

SAS Institute. 1990. SAS/ STAT user's guide, version 6, 4th ed., volume 2. SAS Institute, Inc., Cary, N orth Carolina, 1739 pp.

Schwerdt, R. W., F. P. Ho, and R. R. Watkins. 1979. Meteorological criteria for standard project hurricane and probable maximum hurricane windfields, gulf and east coasts of the United States. NOAA Technical Report NWS 23. U.S. Department of Commerce, National O ceanic and Atmospheric Administration, N ational Weather Service, Washington, DC, $317 \mathrm{pp}$.

Simpson, R. H., and H. Riehl. 1981. The hurricane and its impact. Louisiana State University Press, Baton Rouge, Louisiana, $398 \mathrm{pp}$.

Smith, R. A., and R. E. Deyle. 1997a. A risk-based tax for funding local emergency management costs. Paper presented at the Coastal Zone '97 Conference, Boston, Massachusetts.

Smith, R. A., and R. E. Deyle. 1997b. Blue-sky or morning-after planning for hurricane recovery: a case study of the Florida panhandle following hurricane O pal. Pages 238-285, in J. Schwab (ed.), Planning for post-disaster recovery and reconstruction. Planning Advisory Report. American Planning Association, Chicago.

SWFRPC (Southwest Florida Regional Planning Council). 1982. South west Florida hurricane loss study. SWFRPC, Fort Meyers, Florida, $261 \mathrm{pp}$.

USACE (US Army Corps of Engineers). 1990. Tri-state hurricane property loss study: Executive summary and technical data report. USACE Mobile District, Mobile, Alabama, $132 \mathrm{pp}$.

USBLS (US Department of Commerce, Bureau of Labor and Statistics). 1996. Consumer price indexes. Internet: http:/ / stats.bls.gov/ cpihome.htm (1 January 1997). 
US Census (US Department of Commerce, Bureau of the Census). 1990a. 1990 census of population, general population characteristics, Florida, CH-1-11. USDO C, Washington, DC, 1009 pp.

US Census (US Department of Commerce, Bureau of the Census). 1990b. 1990 census of population, social and economic characteristics, Florida, CPH-2-11. U SDO C, Washington, DC, $2030 \mathrm{pp}$.

Watson, C. C. 1995. The arbiter of storms: A high resolution, GIS based system for integrated storm hazard modeling. National Weather Digest 20(2):2-9. 